\title{
Development of an observational measure of social disinhibition after traumatic brain injury \\ Katherine Osborne-Crowley ${ }^{1}$, Skye McDonald ${ }^{1}$, Heather Francis \\ ${ }^{1}$ School of Psychology, The University of New South Wales
}

Word Count: 6373 (excl. title page, abstract, references, tables and figures)

$\underline{1^{\text {st }} \text { Author (corresponding) }}$

Katherine Osborne-Crowley

School of Psychology,

The University of New South Wales, New South Wales, 2052, Australia

Email: k.osbornecrowley@unsw.edu.au

Phone: +61293853590

$\underline{2^{\text {nd }} \text { Author }}$

Skye McDonald

School of Psychology,

The University of New South Wales, New South Wales, 2052, Australia

Email: s.mcdonald@unsw.edu.au

$\underline{3^{\text {rd }} \text { Author }}$

Heather Francis

School of Psychology,

The University of New South Wales, New South Wales, 2052, Australia

Email: h.francis@unsw.edu.au

Osborne-Crowley, K., McDonald, S., \& Francis, H. (2016). Development of an observational measure of social disinhibition after traumatic brain injury. Journal of clinical and experimental neuropsychology, 38(3), 341-353. 
Abstract

31 Introduction: This study aimed to validate a new observational measure of socially

32 disinhibited behaviour for use in a population of individuals with traumatic brain injury

33 (TBI).

34 Method: Participants were twenty-two adults with severe TBI (mean age of 50.45 years) and

21 healthy comparison participants (mean age 45.29 years). Ratings of observed social

disinhibition were correlated with the disinhibition domain scores of the Neuropsychiatric

Inventory (NPI-D) and with Sydney Psychosocial Reintegration Scale (SPRS) scores. A

regression analysis was undertaken to determine whether formal measures of disinhibition could predict observed disinhibition.

Results: The inter-rater absolute agreement for the social disinhibition ratings was good,

$\mathrm{ICC}=.69$. Participants with TBI were rated as significantly more disinhibited than comparison participants, $t(25.05)=-2.07, p=.049$. The ratings were positively correlated with the NPI frequency score $(r=.45, p=.038)$ and distress score $(r=.45, p=.035)$. The ratings were not related to change in employment or in interpersonal relationships on the SPRS and formal measures of disinhibition were unable to predict observed social disinhibition.

46 Conclusions: This study demonstrates good inter-rater reliability and construct validity of the observational measure. The results evidence the usefulness of this measure and the NPI-D for detecting social disinhibition after TBI.

Keywords: social disinhibition, traumatic brain injury (TBI), observational measure, Neuropsychiatric Inventory (NPI) 
Disruption to social competence after traumatic brain injury (TBI) is often reported to

be the most disabling and distressing outcome for family and for the community (Brooks \& McKinlay, 1983; McKinlay, Brooks, Bond, Martinage, \& Marshall, 1981). A particularly debilitating behaviour change commonly reported after a TBI is social disinhibition (Bigler, 1989; Goldstein, 1952; Jennett \& Teasdale, 1981; Lezak \& O'Brien, 1988; Prigatano, Pepping, \& Klonoff, 1986), which can be defined as "socially inappropriate verbal, physical or sexual acts which reflect a loss of inhibition or an inability to conform to social or cultural behavioural norms"(Arciniegas \& Wortzel, 2014, p. 39). Social disinhibition likely results in difficulty maintaining social relationships post-injury, which may lead to social isolation and psychiatric illness such as depression and anxiety (Brooks, Campsie, Symington, \& Beattie, 1987; Gould, Ponsford, Johnston, \& Schonberger, 2011; Hoofien, Gilboa, Vakil, \& Donovick, 2001; Lezak \& O'Brien, 1988; Malia, Powell, \& Torode, 1995; Morton \& Wehman, 1995; Ponsford, Olver, \& Curran, 1995; Winkler, Unsworth, \& Sloan, 2006). In fact, lack of social connectedness has been reported as the most disabling handicap in daily life 10-15 years post injury (Thomsen, 1984). This loss of social contact has also been found to predict a decrease in life satisfaction for the individual with TBI (Koskinen, 1998). A recent study found that disinhibition was related to suicidal endorsement after TBI at both six and 12 months post injury (Juengst, Kumar, Arenth, \& Wagner, 2014). As well as suffering problems with long-term social reintegration, those with social disinhibition may also encounter vocational and legal problems as a result of their social dysfunction (Malia et al., 1995).

Social disinhibition after TBI also has important implications for the caregiver. One study, for instance, found that in mothers of individuals with TBI, higher emotional distress was observed in those who reported poorer emotional control in their sons on the Current Behaviour Scale (Kinsella, Packer, \& Olver, 1991). Brooks and McKinlay (1983) 
demonstrated that those carers reporting more burden rated their relative with a TBI as more childish compared with pre-injury. In fact, behavioural changes such as disinhibition are often reported to be a greater burden to caretakers than physical or cognitive impairments (Brooks et al., 1987; Kinsella et al., 1991).

Although the burden of social disinhibition following TBI has been well documented, the prevalence of this debilitating syndrome has been difficult to ascertain due to an inconsistency of measurement across studies. Early studies investigating the psychosocial sequelae of TBI reported rates between 30 and $80 \%$ of behaviours characteristic of a disinhibition syndrome, such as "childishness" and "talking too much" (Brooks et al., 1987; Oddy, Coughlan, Tyerman, \& Jenkins, 1985; Ponsford et al., 1995; Thomsen, 1984). Most recently, three studies have employed the Neuropsychiatric Inventory (NPI; Jeffrey L Cummings, 1997) to determine rates of a range of neurobehavioural problems in groups of individuals with TBI. The NPI was originally developed for use in dementia patients and utilises informant ratings to evaluate neurobehavioral disturbances across 12 domains. The disinhibition domain of the NPI (NPI-D) measures the presence of 7 disinhibited behaviours which are commonly described after TBI, as well as assessing the frequency and severity of these symptoms and the level of distress they cause the informant. Studies using the NPI in groups of people with moderate to severe TBI have found rates of $22 \%, 28 \%$ and $32 \%$ of disinhibition (Cantagallo \& Dimarco, 2002; Ciurli, Formisano, Bivona, Cantagallo, \& Angelelli, 2011; Monsalve, Guitart, Lopez, Vilasar, \& Quemada, 2012). These studies represent the best estimates of the frequency of social disinhibition after TBI and have demonstrated the usefulness of the NPI for detecting the disinhibition syndrome in populations of individuals with TBI.

Typically, studies that have examined social disinhibition in people with TBI have utilised self-report or informant-rated measures. These methods of measurement may 
represent unreliable and invalid indicators of behaviour as they are subject to the biases of the patient and the informant. Self-report measures of social behaviour may be impacted by patient's cognitive deficits such as memory or language disturbances or difficulty with selfmonitoring and self-awareness (Ciurli et al., 2011). Informant-report questionnaires, which represent the most common method of measuring social disinhibition after TBI, can be influenced by the personality structure or mood state of the informants (Milders, Fuchs, \& Crawford, 2003; Prigatano, 1992). As an alternative, observational measures overcome these pitfalls of self- and informant-ratings of behaviour and represent a reliable and ecologically valid method of quantifying social disinhibition after TBI. A number of studies have used observational measures to assess social behaviour in people with TBI. These studies, however, have tended to focus on impairments in a broad range of social skills and pragmatic language use, rather than social disinhibition specifically. Evenso, a number of the specific behaviours measured in these studies do overlap with behaviours characteristic of a social disinhibition syndrome, such as inappropriate topic of conversation, self-disclosure and humour. In one study, for example, subjects were rated on an interaction with an opposite-sex stranger by two clinical psychologists on the revised Behavioural Referenced Rating System of Intermediate Social Skills (BRISS-R; Marsh \& Knight, 1991). Participants with TBI were rated as less appropriate on the partner-directed behaviour scale, which measured self-centred behaviour and partner involvement. In another study, participants with TBI were rated using the BRISS-R scales during a videotaped interaction with a confederate (McDonald, Flanagan, Martin, \& Saunders, 2004). This study found that while means for the BRISS scales fell within the normal range, the large range of scores on the "use of humour", "egocentric behaviour" and "partner involvement" scales indicated that a number of individuals with TBI were interacting in a socially inappropriate manner. In another study, 15 minute interactions with a stranger were rated in terms of the aptness of the subject's contribution to the 
conversation, including appropriateness of subject matter and how personal or impersonal the content was (Bond \& Godfrey, 1997). The group of participants with TBI was rated as less appropriate than the orthopaedic controls. Finally, Votruba et al. (2008) concluded that behavioural observation is required to identify disinhibition in the presence of global deficits, since neuropsychological tests had poor specificity. Overall, while the observational measures used to date have demonstrated aberrant social behaviour among participants with TBI, they have not been designed specifically to reflect social disinhibition after TBI. More recently, observational measures targeting social disinhibition more specifically have been used in patients with lesions of the orbitofrontal cortex. Such lesions are known to cause a disinhibition syndrome similar to what is commonly reported after a TBI (Blair \& Cipolotti, 2000; Namiki et al., 2008). In a study by Beer, Heerey, Keltner, Scabini, and Knight (2003) orbitofrontal patients were provided with emotional terms and were asked to provide an example of an occasion on which they had felt that particular emotion. Patients with orbitofrontal lesions disclosed unnecessarily intimate details about this past experience compared with controls. This group were also rated as exhibiting more inappropriately intimate and hostile 'teasing behaviour' when asked to generate a nickname for an unfamiliar person. In another study, Beer, John, Scabini, and Knight (2006) had expert judges rate transcripts of a structured conversation in which orbitofrontal patients were asked a predetermined set of 9 questions by an experimenter. Patients with orbitofrontal damage were rated as self-disclosing more inappropriately than were patients with lateral prefrontal lesions and healthy controls. These studies demonstrate that socially disinhibited behaviours can be observed and reliably assessed in the laboratory. However, this observational measure has not yet been used in a TBI population.

The current study aimed to validate a modified version of the observational measure of socially disinhibited behaviour developed by Beer et al. (2006) for use in a population of 
individuals with TBI. It was hypothesised that the ratings of observed social disinhibition in the laboratory would correlate with informant ratings of socially disinhibited behaviours on the NPI-D. The study also aimed to determine whether this observational measure could predict interpersonal and occupational outcomes for people with a TBI measured by informant ratings on the Sydney Psychosocial Reintegration Scale (SPRS; Tate, Hodgkinson, Veerabangsa, \& Maggiotto, 1999). Since social disinhibition is known to have a deleterious effect on employment status and on interpersonal relationships, it was hypothesised that ratings of observed social disinhibition would predict negative change on these variables since time of injury.

The current study further aimed to determine whether neuropsychological measures might predict social disinhibition after TBI. Case studies of individuals with acquired social disinhibition have often reported normal performance on a range of neuropsychological tests (Cicerone \& Tanenbaum, 1997; Damasio, Grabowski, Frank, Galaburda, \& Damasio, 1994; Eslinger \& Damasio, 1985). Tate (1999) however, found that participants with TBI who were impaired on a rule breaking variable, which was comprised of rule breaks on a verbal fluency and a design fluency task, had higher Loss of Emotional Control scores on the Current Behaviour Scale. Further, McDonald, Hunt, Henry, Dimoska-Di Marco, and Bornhofen (2010) found that, in participants with TBI, disinhibition measured by Hayling Sentence Completion Test and Trail Making Test errors was associated with emotional disinhibition measured using anger ratings after watching anger-inducing film clips. In contrast, though, Milders et al. (2003) found no association between rule break errors on a fluency task and socio-emotional functioning measured by a number of informant-report questionnaires. Thus, there is some evidence for the ability of formal measures of disinhibition to predict disinhibited behaviour. No studies, however, have examined whether neuropsychological measures of disinhibition can predict observed disinhibition in a social context. In line with 
this past research, it was predicted that in the TBI group performance on neuropsychological tasks reflecting disinhibition (the Hayling Sentence Completion Task and Controlled Oral Word Association Task) would predict greater observed disinhibition, while scores on neuropsychological tasks reflecting other aspects of executive function (processing speed and working memory) would not.

\section{Methods}

\section{Participants}

Twenty-two adults (17 males) who had sustained a severe traumatic brain injury of mean age 50.45 years ( $S D=14.30$, range: 24 to 69$)$ with an average of 12.8 years of formal education ( $S D=2.37$, range: 9 to 17$)$ participated. Participants were recruited from the outpatient records of three metropolitan brain injury units in Sydney. Included participants met the following criteria: they had sustained a severe TBI resulting in at least one day of altered consciousness (Russell \& Smith, 1961), were discharged from hospital and living in the community, and were proficient in English. Prior to the TBI, the participants had been employed in occupations ranging from unskilled $(n=3)$ to skilled trade $(n=1)$, professional or managerial $(n=10)$, business owner $(n=2)$, and study $(n=6)$. The participants with TBI had experienced post-traumatic amnesia (PTA) ranging from 2 to 189 days $(M=64.57, S D=$ 46.52), and participated in the study from 2 to 45 years post-injury $(M=14.95, S D=12.04)$. PTA scores were obtained from patient medical records with an exception of one participant whose records were unavailable. In this case, the injury was recorded as severe because coma duration exceeded 24 hours (Corrigan, Selassie, \& Orman, 2010). The participants' injuries were sustained as a consequence of motor vehicle and motorbike accidents $(n=13)$, falls $(n=7)$, assaults $(n=1)$ and occupational injury $(n=1)$. CT scans acquired from medical records revealed that the injuries sustained by the participants were heterogeneous and included skull fractures, contusions, intracerebral and subdural or subarachnoid haemorrhages. Injuries 
203

204

205

206

207

208

209

210

211

212

213

214

215

216

217

218

219

220

221

222

223

224

225

226

227

included bilateral frontal $(n=5)$, right frontal $(n=5)$, left frontal $(n=1)$, bilateral temporal $(n=2)$, right temporal $(n=3)$, left temporal $(n=2)$, left parietal $(n=2)$, right parietal $(n=2)$, right occipital $(n=2)$, left occipital $(n=2)$ and unknown $(n=3)$. Table 1 provides descriptive data outlining the cognitive and emotional status of the TBI group. Informant-report questionnaires were completed by a family member, spouse or close friend of each participant with TBI. These informants had all known the participant well before the injury and had been in close contact since the injury. The same informant always completed both questionnaires. Comparison participants were 21 adults (18 males) without brain injury with a mean age of $45.29(S D=13.70$, range: 22 to 68$)$ and an average of 14.52 years of education $(S D=1.69$, range: 11 to 18$)$. The comparison group was recruited from the community via online and local newspaper advertisements. The comparison participants were employed in a variety of occupations including professional and managerial $(n=10)$, business owner $(n=1)$, unemployed $(n=3)$ and student $(n=7)$. Exclusion criteria for both groups included a history of developmental, neurological (other than TBI) or psychiatric disorders, or a history of substance abuse.

\section{Materials}

\section{Social Disinhibition Interview.}

The current study used an adaptation of the self-disclosure task developed by Beer et al. (2006). As in the original task, participants were initially told that they would be asked a number of questions about themselves and their experiences, and that it was their choice how much information they wished to disclose and that they could skip any question at any time.

These instructions were designed to minimise an expectation of excessive self-disclosure.

Participants were then asked a series of seven questions, which included: "Tell me about an embarrassing moment you've had" and "Tell me about something someone has done to make you angry". These seven questions included only four of the original nine used by Beers et al 
(2006) as pilot work suggested five were not sensitive. Three new questions were added as replacements. The interviews were videotaped and rated by two independent judges, blind to whether the participant had sustained a TBI or was a comparison participant. Although Beer and colleagues had judges rate transcripts of interviews, we chose to have videotaped interviews rated to give judges a more complete picture of the social appropriateness of the participant, since disinhibited behaviour is not only verbal. Judges rated the frequency of the participants socially inappropriate behaviour on a scale of 1 to 5 ( $1=$ 'never' and $5=$ 'always') on the following 8 statements: 'While talking with the interviewer, the participant spoke too candidly', 'Considering that they didn't know the interviewer very well, the participant disclosed an inappropriate amount of information about themselves', 'The participant revealed more intimate details than most people would', 'The participant was rude', 'The participant made inappropriate jokes or remarks', 'The participant was impatient', 'The participant did not know when to stop talking', 'The participant was critical or argumentative'. Thus, the disinhibition ratings can range from 8 to 40 . The first three statements were from Beer and colleagues scale measuring appropriateness of self-disclosure. The remaining five statements replaced the other statements used by Beers et al (2006) in order to tap a broader range of social behaviours commonly reported following traumatic brain injury. Beer and colleagues had judges rate responses to each of the nine questions posed and then averaged these ratings together. Instead, we chose to have judges rate the whole interview on each of the seven items for the sake of simplicity and brevity. The length of the interview varied depending on the participant but no interview ran longer than 15 minutes. The judges were trained in the use of the rating scales on 5 practice recordings, which were not used in the final data analyses. The judges were asked to watch each recording in full before providing a rating for each of the 8 statements before moving onto the next recording. 


\section{Neuropsychiatric Inventory (NPI).}

The Neuropsychiatric Inventory (NPI; Jeffrey L Cummings, 1997) uses informant

ratings to evaluate neurobehavioural disturbances across 12 domains. Only the disinhibition domain was evaluated for this study. For each domain, a screening question determines whether problems in that domain are present and is followed by 7 to 9 questions that address specific symptoms. The informant then rates the severity and frequency of, as well as the distress caused by these symptoms. The NPI has well-established psychometric properties including an overall Cronbach's alpha of .88, inter-rater agreement ranging from $93.6 \%$ to $100 \%$ for different behaviours, and a 3-week test-retest reliability estimates of .79 for frequency scores and .86 for severity scores (Jeffrey L Cummings, 1997; J. L. Cummings et al., 1994). Since its initial validation in dementia patients, the NPI has been used to successfully describe the neuropsychiatric symptoms of post-stroke (Angelelli et al., 2004) and TBI (Cantagallo \& Dimarco, 2002; Ciurli et al., 2011; Kilmer et al., 2006; Monsalve et al., 2012). For use in a population of individuals with TBI, it has the advantage of having been developed and normed especially for individuals with neurological impairment. The current study did not use the screening question but rather had all caregivers complete the full form. This approach was recommended by Kilmer et al. (2006) who found a high false negative rate for the disinhibition subscale, such that caregivers who did not endorse the screening item went on to endorse a number of metric items. The severity scale was adjusted to include a 'not applicable - disinhibition not present' response item to reflect this. Four scores were derived from the disinhibition domain of the NPI. The frequency score measures how commonly the disinhibited behaviours occur and ranged from 0 (never) to 4 (very often). The severity score measured the severity of the disinhibited behaviours ranging from 1 (not applicable) to 3 (severe). The distress score measured the level of distress that the disinhibited behaviours caused the informant and ranged from 0 (not at all) to 5 (very 
severely). The distress score has been used in dementia research and has been shown to correlate with caregiver distress on the Relative's Stress Scale and caregivers quality of life measured by the Quality of Life - Alzheimer's Disease scale (Kaufer et al., 1998; Shin, Carter, Masterman, Fairbanks, \& Cummings, 2005). The disinhibition total score was the addition of the frequency, severity and distress scores.

\section{Sydney Psychosocial Reintegration Scale (SPRS).}

The Sydney Psychosocial Reintegration Scale 2 (SPRS-2 Form A; Tate et al., 1999) was completed by a relative or close friend of each participant with TBI. The SPRS-2 was designed to measure reintegration of people after TBI in three domains; occupation, interpersonal relationships and independent living skills. In each domain there are four items, which measure the degree of negative change in a particular behaviour or activity due to the injury. Response items range from 0 (an extreme amount of negative change) to 4 (no change or improvement).Total scores for each domain range from 0 to 16 , with higher scores representing betters levels of psychosocial reintegration. The SPRS has good psychometric properties. A high inter-rater reliability $(\mathrm{ICC}=0.95)$, and 1-week test-retest reliability (ICC $=0.90)$, as well as good concurrent validity with the London Handicap Scale $\left(r_{\mathrm{s}}=-0.85\right)$, has been demonstrated for Form A of the SPRS-2 (Tate et al., 1999). The current study only examined scores for the occupation and interpersonal relationships domains. Missing data $(<$ $5 \%$ in each variable) for both the NPI and the SPRS questionnaires were replaced by values imputed using the expectation maximization algorithm in SPSS's Missing Value Analysis.

\section{Neuropsychological measures.}

In order to determine whether neuropsychological tests of disinhibition predicted observed disinhibition in the TBI group, two inhibition measures were used: total errors on the Controlled Oral Word Association Test (COWAT; Spreen \& Strauss, 1991) and the 
Hayling Sentence Completion Test (Burgess \& Shallice, 1997) error scaled score. These scores have been used previously as measures of disinhibition after TBI or orbitofrontal neurodegeneration (Crowe \& Crowe, 2013; Hornberger, Geng, \& Hodges, 2011; Tate, 1999).

The COWAT tests phonemic fluency (C, F, L) and semantic fluency (animals) and errors include complete and partial repetitions of words (e.g., "sleep" and "sleeping") and rule breaks (i.e., wrong letter or category, proper nouns, swear words etc.). Participants are explicitly told what constitutes an error in this task. A high total error score thus represents an inability to inhibit 'illegal words' in this task. The Hayling Sentence Completion Test requires the subject to complete sentences in Section 1 with semantically related words (the control condition) and then in Section 2 with semantically unrelated words, which requires inhibiting a prepotent response (the inhibition condition). The number of errors on Section 2 of the Hayling Test is converted to the Hayling error scaled score which ranges from 1 (impaired) to 8 (good). Thus, a low error scaled score represents a relative inability to inhibit prepotent responses. Participants also completed a measure of working memory, Wechsler Adult Intelligence Scale-Third Edition (WAIS-III) Digit Span (Wechsler, 1997), and a measure of processing speed, WAIS-III Digit Symbol Coding which were used to test the divergent validity of the observational measure of disinhibition. Neuropsychological measures were not available for the comparison group.

The presence of negative emotional states was assessed using the 21 item Depression, Anxiety and Stress Scale (DASS; Lovibond \& Lovibond, 1995). A total score was derived by summing the scores for the three subscales.

\section{Procedure.}

The participants were informed of the procedures and gave written consent to participate in the study. All procedures were approved by the Human Research Ethics Boards 
of the University of New South Wales and were conducted at the university. Participants were administered neuropsychological tests (TBI only), the DASS and finally the observational measure of social disinhibition. Participants with TBI were given a packet of questionnaires which included the SPRS and NPI-D to give to a family member or close friend who has known them well since before their injury. In the packet included instructions for the informant to mail completed questionnaires back. All measures were administered in a single session, with exception of some neuropsychological tests which had been completed by the participant recently as a part of another study run in the neuropsychology laboratory.

\section{Statistical Analyses.}

The inter-rater reliability for ratings across both groups was analysed with an intraclass correlation coefficient (ICC) using a two way random model as recommended by Shrout and Fleiss (1979). For comparison with Beer et al. (2006), reliability across the two judges' average ratings for each participant was also reported as a Cronbach's alpha. An independent samples t-test was then used to determine whether mean ratings were different for the TBI group compared with the comparison group. Mean disinhibition ratings were then correlated with NPI-D scores to determine the construct validity of the observational measure and with SPRS scores in order to determine whether the measure could predict psychosocial outcome. The NPI-D was also correlated with the SPRS to determine whether informantreported disinhibition predicted psychosocial outcome. Finally, in order to test the hypothesis that formal measures of disinhibition would predict observed social disinhibition whereas working memory and processing speed would not, a multiple regression predicting social disinhibition ratings from those four neuropsychological variables (WAIS-III Digit Span, WAIS-III Digit Symbol Coding, Hayling error scaled score and COWAT error score) was conducted. This model was also run to determine whether neuropsychological performance based tests of disinhibition predicted informant-reported disinhibition on the NPI-D. 
TBI with respect to age, $t(41)=.-1.21, p=.233$, or preinjury occupation $\chi^{2}(1, N=43)=7.39$, $p=.19$. The groups did differ significantly in terms of number of years of education, $t(41)=-$ $2.78, p=.008$ and in terms of mood as assessed by the DASS total score, $t(41)=-3.30, p=.003$.

Years of education and DASS total score were not significantly correlated with the dependent variable, social disinhibition ratings, in either the comparison group $(r=-.02, p=.936$ and $r=.36, p=.110$ respectively) or the groups of participants with TBI $(r=.21, p=.343$ and $r=.34$, $p=.125$ respectively). These variables were therefore not accounted for in following statistical analyses.

Social Disinhibition Ratings

The inter-rater absolute agreement was good (Fleiss, Levin, \& Paik, 2003), ICC=.69, $95 \%$ CI $[.42, .83]$, and was similar when looking at ratings for the group of participants with TBI alone, $\mathrm{ICC}=.68,95 \% \mathrm{CI}[.25, .87]$. The reliability across the two judges' ratings indicated by Cronbach's alpha was also acceptable (Barker, Pistrang, \& Elliot, 1994); $\alpha=.71$ when all participants ratings were included in analysis and $\alpha=.70$ when only participants with TBI were considered. An average of the two ratings for each participant was calculated and was used in all analyses that follow.

A Levene's test for the equality of variances revealed that the variances for the TBI and comparison group were significantly different, $F(1,41)=7.55, p=.009$. The greater variance in the group of participants with TBI can be observed in Figure 1. An independent samples t-test with equal variances not assumed revealed a larger mean social disinhibition rating for participants with TBI compared with the comparison group, $t(25.05)=-2.07$, $p=.049$. Four of the $22(18 \%)$ participants with TBI had social disinhibition ratings greater than 2 standard deviations above the comparison group mean and 7 (32\%) had ratings greater 
than 1 standard deviation above the comparison group mean. This compares to 1 of the 21 (4\%) comparison participants who had a social disinhibition rating greater than 2 standard deviations above the mean and 2 of 21 (9\%) who had ratings greater than 1 standard deviation above the mean.

The social disinhibition ratings were significantly correlated with the NPI-D frequency score $(r=.45, p=.038)$ and distress score $(r=.45, p=.035)$, but not with the severity score $(r=.12, p=.61)$. The social disinhibition ratings did not correlate with either of the outcome measures, the occupation subscale $(r=.02, p=.916)$ nor interpersonal relationships subscales $(r=-.12, p=.610)$ of the SPRS.

Table 2 shows the correlations between observed and informant-rated disinhibition and neuropsychological measures of disinhibition and of executive functioning. Contrary to our hypothesis a regression model with WAIS-III Digit Span, WAIS-III Digit Symbol Coding, Hayling error scaled score and COWAT error score did not significantly predict social disinhibition ratings, $F(4,20)=2.31, p=.103$, adj. $R^{2}=.21$, as shown in Table 3 .

\section{Neuropsychiatric Inventory}

Sixteen (16) of the $22(73 \%)$ participants with a TBI were reported by an informant to display at least one of the 7 disinhibited behaviours measured by the NPI-D. Table 4 shows the number of participants reported to display each of the behaviours. Of the outcome measures, the NPI disinhibition total score was correlated with the interpersonal relationships subscale of the SPRS ( $r=-.42, p=.049)$, but not with the occupation subscale $(r=-.13, p=.564)$. A multiple regression analysis revealed that, combined, WAIS-III Digit Span, WAISIII Digit Symbol Coding, Hayling error scaled score and COWAT error score did significantly predict NPI-D total score, $F(4,20)=4.24, p=.016$, adj. $R^{2}=.39$. Of the four 
neuropsychological measures, only the COWAT error score added significantly to the prediction, $p=.019$, as demonstrated in Table 3 .

\section{Discussion}

The current study aimed to validate the use of a short observational measure for the detection of social disinhibition in a population of individuals with TBI. Acceptable interrater reliability was observed for the measure (Barker et al., 1994). Further, positive correlations between mean disinhibition ratings and frequency and distress scores for the disinhibition domain of the NPI provide evidence for the measure's construct validity. The relationship between ratings of observed disinhibition and the reported frequency of disinhibited behaviour by an informant is easily understood, since disinhibited behaviour that is more common will be more likely to occur in the timeframe during which the patientexperimenter interaction was recorded. The relationship between ratings of observed disinhibition and the level of distress relatives report on the NPI-D demonstrates the sensitivity of the observational measure to social disinhibition which has important implications for the patient's life. It should be noted, however, that these correlations, although significant, were only moderate in size. Although a stronger correlation would have provided greater confidence in the construct validity of this measure, this correlation of only moderate size demonstrates the difficulty of developing an observational measure as sensitive to behaviour as an informant measure, which is based on endless observations in more natural social settings. Further research should attempt to verify this relationship between disinhibition observed in the laboratory and disinhibition reported by close others. Finally, it is of interest that while the frequency and distress scores did correlate with observed disinhibition, the severity score did not. This may reflect that a disinhibited behaviour rated as severe in a natural social setting may not translate to a particularly severe behaviour in an interview setting. For instance, sharing intimate and personal details with a stranger might be 
considered an extremely disinhibited behaviour when meeting new people at a social occasion, but may not be judged as so severe in the context of answering specific questions posed by an interviewer in a psychological study.

As predicted, participants with TBI were rated as more socially disinhibited on average than comparison participants. Further, the ratings for participants with TBI displayed more variability than those for comparison participants. This suggests that while some participants with TBI behaved in a socially appropriate manner during the interview task, the social behaviour of others lay outside the normal range. In fact, 19 percent of the participants with TBI had social disinhibition ratings greater than 2 standard deviations above the comparison group mean. When comparing this to rates of $22-32 \%$ of social disinhibition reported by studies using the disinhibition domain of the NPI (Cantagallo \& Dimarco, 2002; Ciurli et al., 2011; Monsalve et al., 2012), the observational measure might be considered a conservative measure of social disinhibition. False negative rates are to be expected, though, since a disinhibition syndrome observed over time by a relative or friend may not reveal itself within the relatively small time window of the observed conversation. As an alternative to informant-report measures, this observational measure may represent a simple method of quantifying socially disinhibited behaviours in the laboratory. It represents one of the few measures designed specifically to detect disinhibited behaviour resulting from TBI and may be a useful tool for determining what factors might contribute to social disinhibition and how it can be rehabilitated.

Contrary to predictions, though, the observational measure developed in the current study was unable to predict outcomes such as changes in employment or in interpersonal relationships since the time of injury, as assessed by the SPRS. No other studies have tested the ability of an observational measure of social skill to predict outcomes after TBI. On the other hand, the NPI-D total score was associated with greater change in interpersonal 
relationships since injury. Thus, participants who were rated as more disinhibited on the NPI-

D were also rated as suffering greater change in their ability to form and maintain interpersonal relationships since the injury. Two studies have demonstrated the ability of the disinhibition domain of the NPI to predict score on the Glasgow Outcome Scale, which indicates how much assistance with daily living a patient with TBI requires (Cantagallo \& Dimarco, 2002; Ciurli et al., 2011; Monsalve et al., 2012). The current study is the first to demonstrate the ability of the disinhibition domain of the NPI to predict social outcomes after TBI. These findings together reveal how significant the impact of social disinhibition is on the everyday functioning and wellbeing of the individual with TBI. It can be concluded that informant-report measures of social disinhibition may be more predictive than observational measures of important outcomes such as ability to maintain existing relationships and form new relationships.

The current study found that $71 \%$ of the group of participants with TBI displayed at least one of the disinhibited behaviours described by the metric items of the NPI according to their relative. The most frequently endorsed items were acting impulsively, speaking to strangers as if he/she knew them, and being insensitive. The same three items were reported by Cantagallo and Dimarco (2002) to be the most frequently endorsed in a sample of 120 participants with severe TBI with endorsement rates of 58,53 and $34 \%$ for these three items respectively, compared with endorsement rates of $54 \%, 50 \%$ and $36 \%$ for the same items in the current study. Studies using the screen-metric approach of the NPI, whereby an informant only continues on to complete the full domain form if a screening question is endorsed, have reported rates of disinhibition in populations of individuals with TBI (23\%, 28\% and $32 \%)$ much lower than that found in the current study (Cantagallo \& Dimarco, 2002; Ciurli et al., 2011; Monsalve et al., 2012). Kilmer et al. (2006) though, demonstrated that the screening question for the disinhibition domain of the NPI when used in a population of individuals 
with TBI produced a high false negative rate whereby $11.9 \%$ of informants not endorsing the screening question went on to endorse one or more of the metric items. Thus, the aforementioned studies utilising the screen-metric approach of the NPI in populations of individuals with TBI may have underestimated rates of disinhibition. The findings of the current study support the recommendations of (Kilmer et al., 2006) that the screening question for the disinhibition domain of the NPI be omitted for use in a population of individuals with TBI.

Contrary to our hypothesis a multiple regression revealed that neuropsychological measures of disinhibition were unable to predict observed disinhibition in the current study. This is in line with Votruba et al. (2008) who found that in vivo ratings of disinhibited behaviour and performance tests dissociated. The authors concluded that disinhibited behaviour is optimally assessed using observations, since performance tests had poor specificity, showing strong associations with tests of other neuropsychological domains. The COWAT error score, however, did significantly predict the informant-reported disinhibition reflected by the NPI-D total score, demonstrating the ability of formal measures of disinhibition to predict informant-reported disinhibition. Similarly, Tate (1999) found that participants impaired on a rule breaking variable which included the COWAT error score had higher informant-reported loss of emotional control on the Current Behaviour Scale.

However, Tate noted that these errors were most often perseverative errors rather than error indicative of inability to inhibit responding. Further, informant ratings of externalising behaviours on the Iowa Scales of Personality Change (ISPC), which measure many behaviours characteristic of disinhibition syndrome, have been found to be associated with a test of broad executive function, the Modified Six Element Test (Rochat, Ammann, Mayer, Annoni, \& Van der Linden, 2009). Another study found no association between inappropriateness on the Neuropsychology Behaviour and Affect Profile after TBI and rule- 
breaks on two fluency tasks (Milders et al., 2003). Thus, while the current study provides some evidence that neuropsychological tests of inhibitory function are associated with informant-reported disinhibited behaviours, further research is required to determine processes underlying these errors on neuropsychological tests which are associated with disinhibited behaviour. That the current study, did not find evidence that performance-based neuropsychological measures of disinhibition can predict observed disinhibition in a social context may reflect that the observational measure is likely to be a more conservative measure of disinhibition than the NPI which may impact upon its associations with other measures of disinhibition.

There are some limitations of the current study that should be noted. The relationship found between informant-report disinhibition and informant-reported change in interpersonal relationships may be the result of a single source bias, since the same informant filled out both questionnaires. To verify this relationship, further research should use the NPI-D in a TBI sample alongside an objective or self-report measure of psychosocial outcome. Another limitation of the current study was that the TBI sample varied greatly with respect to time since injury. Thus, it cannot be determined whether disinhibited behaviour observed in participants developed as a direct result of their injury or if the behaviours developed later perhaps as the result of advanced age interacting with injury-related changes. Future research should aim to determine whether the disinhibition ratings provided by judges on this observational measure reflect an organic disinhibition syndrome appearing as a result of injury to the frontal lobe brain structures which underpin normal social functioning.

The current study reported promising findings of good inter-rater reliability and construct validity of a new observational measure for the detection of social disinhibition after TBI. The direct observation of specific behaviours enables a targeted measure of disinhibition after TBI which is not subject to biases of the patient or informant associated 
524 with memory of the behaviour across long periods of time, insight into the behaviour or the

525 personality or mood state of the informant. Thus, this measure represents a good alternative

526 research tool to self- and informant-report measures and may be useful in a clinical setting to

527 identify problem behaviours for targeted intervention. However, more extensive research will

528 be required before this tool can be used with confidence for research or clinical purposes.

529 Further, the current study demonstrated that formal measures of disinhibition can predict

530 informant rated disinhibition but not disinhibition observed in the laboratory, providing some

531 support for the use of formal tests of disinhibition as a corollary for disinhibited social

532 behaviour. Finally, this study indicated the usefulness of the disinhibition domain of the

533 Neuropsychiatric Inventory for detecting disinhibition syndromes and for predicting occupational and interpersonal outcomes in populations of individuals with TBI. 


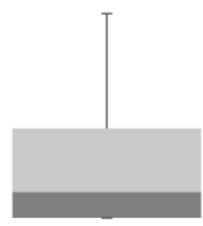

Control Group

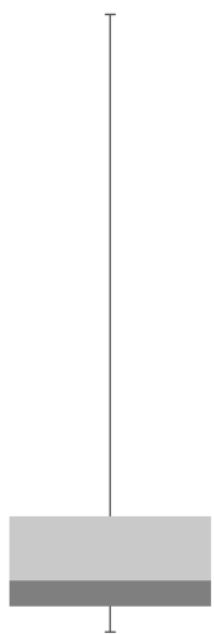

TBI Group

Figure 1. Boxplots of the social disinhibition ratings comparing variability in scores between the comparison group and group of participants with TBI. Whiskers represent the maximum and minimum mean ratings for each group.

539

540

541

542

543

544

545

546

547

548

549 
551 Table 1

552 Means, standard deviations and results of group comparisons on demographic, emotional 553 and cognitive variables for the TBI and comparison groups

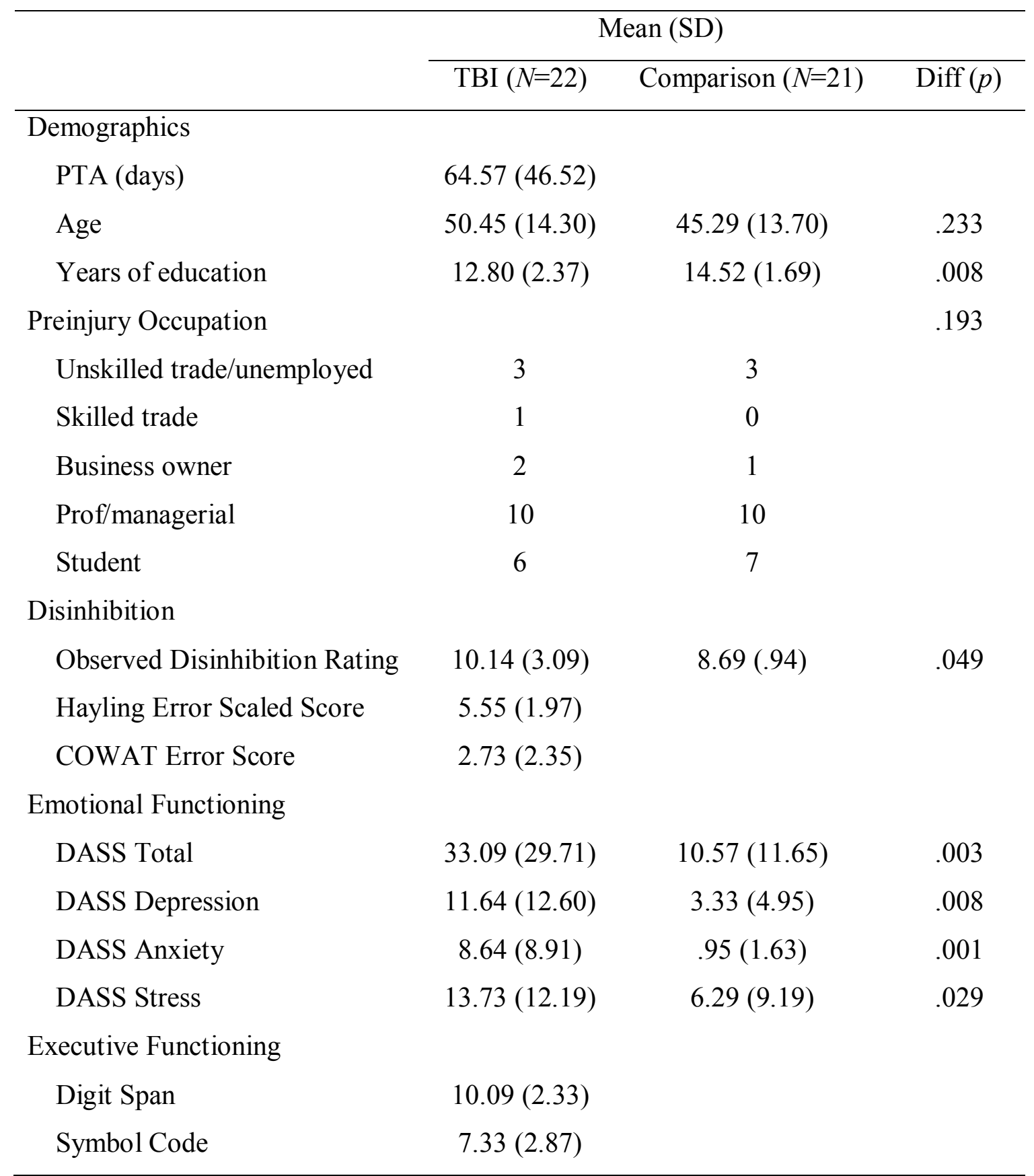


558

559

560

\begin{tabular}{lllllll}
\hline & $\begin{array}{l}\text { NPI } \\
\text { total } \\
\text { score }\end{array}$ & $\begin{array}{l}\text { Mean } \\
\text { disinhibition } \\
\text { rating }\end{array}$ & $\begin{array}{l}\text { Hayling } \\
\text { scaled } \\
\text { error } \\
\text { score }\end{array}$ & $\begin{array}{l}\text { COWAT } \\
\text { error } \\
\text { score }\end{array}$ & $\begin{array}{l}\text { Digit } \\
\text { span }\end{array}$ & $\begin{array}{l}\text { Digit symbol } \\
\text { coding }\end{array}$ \\
\hline $\begin{array}{l}\text { Informant-Reported Disinhibition } \\
\quad \text { NPI Total Score }\end{array}$ & & .38 & .34 & $.70^{* *}$ & $.48^{*}$ & .26 \\
$\begin{array}{l}\text { Observed Disinhibition } \\
\quad \text { Disinhibition mean rating }\end{array}$ & .38 & & .14 & .41 & .07 & -.09 \\
$\begin{array}{l}\text { Neuropsychological Disinhibition } \\
\text { Hayling error scaled score }\end{array}$ & .34 & .14 & & .30 & .09 & .19 \\
$\quad \begin{array}{l}\text { COWAT error score } \\
\text { Neuropsychological Exec Func }\end{array}$ & $.70^{* *}$ & .41 & .30 & & .19 & $.52^{*}$ \\
$\quad$ & & & & & & \\
$\quad \begin{array}{l}\text { Digit span } \\
\text { Digit symbol coding }\end{array}$ & $.48^{*}$ & .07 & .09 & .19 & .09 & .09 \\
\hline
\end{tabular}

561

Note. Exec Func=Executive Functioning. $*$ Significant at $p<.05$. ** Significant at $p<.001$.
562

563

564

565

\begin{tabular}{lcccc}
\hline & \multicolumn{2}{c}{ Social Disinhibition Ratings } & \multicolumn{2}{c}{ NPI Disinhibition total Score } \\
\cline { 2 - 5 } Variable & $\mathrm{B}$ & $\beta$ & $\mathrm{B}$ & $\beta$ \\
\hline Constant & 10.27 & & -3.78 & \\
Digit Span & .09 & .07 & .42 & .37 \\
Digit Symbol Code & -.50 & -.45 & -.09 & -.10 \\
COWAT Error & $1.05^{*}$ & $.69^{*}$ & $.68^{*}$ & $.55^{*}$ \\
Hayling Error & -.001 & -.001 & .24 & .19 \\
& & & & $.39^{*}$ \\
Adjusted $\mathrm{R}^{2}$ & & .21 & & $4.24^{*}$ \\
F & & 2.31 & &
\end{tabular}

Table 3

Multiple regressions predicting social disinhibition ratings and NPI-D total score from four neuropsychological variables

Note. $\mathrm{N}=21 * \mathrm{p}<.05$ 
Table 4

569 The most frequently endorsed metric items of the disinhibition domain of the

570 Neuropsychiatric Inventory (NPI-D)

\begin{tabular}{llc}
\hline Response item & $\begin{array}{l}\text { Number of } \\
\text { Participants }\end{array}$ & Percentage \\
\hline Does he/she act impulsively without thinking of the consequences & 12 & $54 \%$ \\
$\begin{array}{l}\text { Does he/she talk to strangers as if they knew them } \\
\text { Does he/she say things to people that are insensitive or hurt their }\end{array}$ & 8 & $50 \%$ \\
$\begin{array}{l}\text { feelings } \\
\begin{array}{l}\text { Does he/she talk openly about very personal or private matters not } \\
\text { usually discussed in public }\end{array}\end{array}$ & 5 \\
$\begin{array}{l}\text { Does he/she show other signs of loss of control of his/her impulses } \\
\text { Does he/she say crude things or make inappropriate sexual remarks }\end{array}$ & 5 & $23 \%$ \\
$\begin{array}{l}\text { Does he/she fondle, touch or hug others in a way that is not } \\
\text { appropriate }\end{array}$ & 11 & $9 \%$ \\
\hline
\end{tabular}

571 
573

574

575

576

577

578

579

580

581

582

583

584

585

586

587

588

589

590

591

592

593

594

595

596

Angelelli, P., Paolucci, S., Bivona, U., Piccardi, L., Ciurli, P., Cantagallo, A., . . Grasso, M. (2004). Development of neuropsychiatric symptoms in poststroke patients: a crosssectional study. Acta Psychiatrica Scandinavica, 110(1), 55-63. doi: 10.1111/j.16000447.2004.00297.x

Arciniegas, D. B., \& Wortzel, H. S. (2014). Emotional and behavioral dyscontrol after traumatic brain injury. Psychiatric Clinics of North America, 37(1), 31-53. doi: 10.1016/j.psc.2013.12.001

Barker, C., Pistrang, N., \& Elliot, R. (1994). Research methods in clinical and counselling psychology. Research methods in clinical and counselling psychology: John Wiley \& Sons; England.

Beer, J. S., Heerey, E. A., Keltner, D., Scabini, D., \& Knight, R. T. (2003). The regulatory function of self-conscious emotion: insights from patients with orbitofrontal damage. Journal of Personality and Social Psychology, 85(4), 594-604. doi: 10.1037/00223514.85 .4 .594

Beer, J. S., John, O. P., Scabini, D., \& Knight, R. T. (2006). Orbitofrontal cortex and social behavior: integrating self-monitoring and emotion-cognition interactions. Journal of Cognitive Neuroscience, 18(6), 871-879. doi: 10.1162/jocn.2006.18.6.871

Bigler, E. D. (1989). Behavioural and cognitive changes in traumatic brain injury: a spouse's perspective. Brain Injury, 3(1), 73-78.

Blair, R. J. R., \& Cipolotti, L. (2000). Impaired social response reversal 'A case of acquired sociopathy'. Brain, 123(6), 1122-1141. doi: 10.1093/brain/123.6.1122

Bond, F., \& Godfrey, H. P. (1997). Conversation with traumatically brain injured individuals: A controlled study of behavioural changes and their impact. Brain Injury, 11(5), 319330. 
597

598

599

600

601

602

603

604

605

606

607

608

609

610

611

612

613

614

615

616

617

618

619

620

621

Brooks, N., Campsie, L., Symington, C., \& Beattie, A. (1987). The effects of severe head injury on patient and relative within seven years of injury. The Journal of Head Trauma Rehabilitation, 2(3), 1-13. doi: 10.1097/00001199-198709000-00003

Brooks, N., \& McKinlay, W. (1983). Personality and behavioural change after severe blunt head injury - a relative's view. Journal of Neurology, Neurosurgery \& Psychiatry, 46(4), 336-344. doi: 10.1136/jnnp.46.4.336

Burgess, P. W., \& Shallice, T. (1997). The Hayling and Brixton Tests. San Antonio, TX: Pearson PsychCorp Assessment.

Cantagallo, A., \& Dimarco, F. (2002). Prevalence of neuropsychiatric disorders in traumatic brain injury patients. Europa Medicophysica, 38(4), 167-178.

Cicerone, K. D., \& Tanenbaum, L. N. (1997). Disturbance of social cognition after traumatic orbitofrontal brain injury. Archives of Clinical Neuropsychology, 12(2), 173-188. doi: 10.1093/arclin/12.2.173

Ciurli, P., Formisano, R., Bivona, U., Cantagallo, A., \& Angelelli, P. (2011).

Neuropsychiatric disorders in persons with severe traumatic brain injury: prevalence, phenomenology, and relationship with demographic, clinical, and functional features. The Journal of Head Trauma Rehabilitation, 26(2), 116-126.

Corrigan, J. D., Selassie, A. W., \& Orman, J. A. L. (2010). The epidemiology of traumatic brain injury. The Journal of Head Trauma Rehabilitation, 25(2), 72-80. doi: 10.1097/HTR.0b013e3181ccc8b4

Crowe, S. F., \& Crowe, L. M. (2013). Does the presence of posttraumatic anosmia mean that you will be disinhibited? Journal of Clinical and Experimental Neuropsychology, 35(3), 298-308.

Cummings, J. L. (1997). The Neuropsychiatric Inventory Assessing psychopathology in dementia patients. Neurology, 48(5 Suppl 6), 10S-16S. 
622

623

624

625

626

627

628

629

630

631

632

633

634

635

636

637

638

639

640

641

642

643

644

645

646

Cummings, J. L., Mega, M., Gray, K., Rosenbergthompson, S., Carusi, D. A., \& Gornbein, J. (1994). The Neuropsychiatric Inventory - Comprehensive Assessment of Psychopathology in Dementia. Neurology, 44(12), 2308-2314. doi: 10.1212/WNL.44.12.2308

Damasio, H., Grabowski, T., Frank, R., Galaburda, A. M., \& Damasio, A. R. (1994). The return of Phineas Gage - Clues about the brain from the skull of a famous patient. Science, 264(5162), 1102-1105. doi: 10.1126/science.8178168

Eslinger, P. J., \& Damasio, A. R. (1985). Severe disturbance of higher cognition after bilateral frontal lobe ablation Patient EVR. Neurology, 35(12), 1731-1731. doi: 10.1212/WNL.35.12.1731

Fleiss, J. L., Levin, B., \& Paik, M. C. (2003). Statistical Methods for Rates and Proportions (3rd Edition ed.). Hoboken, NJ: John Wiley \& Sons.

Goldstein, K. (1952). The Effect of Brain Damage on the Personality. Psychiatry, 15(3), 245260.

Gould, K. R., Ponsford, J. L., Johnston, L., \& Schonberger, M. (2011). Relationship between psychiatric disorders and 1-year psychosocial outcome following traumatic brain injury. Journal of Head Trauma Rehabilitation, 26(1), 79-89. doi: 10.1097/Htr.0b013e3182036799

Hoofien, D., Gilboa, A., Vakil, E., \& Donovick, P. J. (2001). Traumatic brain injury (TBI) 10-20 years later: a comprehensive outcome study of psychiatric symptomatology, cognitive abilities and psychosocial functioning. Brain Injury, 15(3), 189-209. doi: $10.1080 / 026990501300005659$

Hornberger, M., Geng, J., \& Hodges, J. R. (2011). Convergent grey and white matter evidence of orbitofrontal cortex changes related to disinhibition in behavioural variant frontotemporal dementia. Brain, 134(9), 2502-2512. doi: 10.1093/brain/awr173 
647

648

649

650

651

652

653

654

655

656

657

658

659

660

661

662

663

664

665

666

667

668

669

670

Jennett, B., \& Teasdale, G. (1981). Management of head injuries: FA Davis Company.

Juengst, S. B., Kumar, R. G., Arenth, P. M., \& Wagner, A. K. (2014). Exploratory associations with tumor necrosis factor-alpha, disinhibition and suicidal endorsement after traumatic brain injury. Brain, Behavior, and Immunity, 41, 134-143. doi: 10.1016/j.bbi.2014.05.02024928066

Kaufer, D. I., Cummings, J. L., Christine, D., Bray, T., Castellon, S., Masterman, D., . . . DeKosky, S. T. (1998). Assessing the impact of neuropsychiatric symptoms in Alzheimer's disease: The Neuropsychiatric Inventory Caregiver Distress Scale. Journal of the American Geriatrics Society, 46(2), 210-215.

Kilmer, R. P., Demakis, G. J., Hammond, F. M., Grattan, K. E., Cook, J. R., \& Kornev, A. A. (2006). Use of the Neuropsychiatric Inventory in traumatic brain injury: A pilot investigation. Rehabilitation Psychology, 51(3), 232.

Kinsella, G., Packer, S., \& Olver, J. H. (1991). Maternal reporting of behaviour following very severe blunt head injury. Journal of Neurology, Neurosurgery \& Psychiatry, $54(5), 422-426$.

Koskinen, S. (1998). Quality of life 10 years after a very severe traumatic brain injury (TBI): the perspective of the injured and the closest relative. Brain Injury, 12(8), 631-648.

Lezak, M. D., \& O'Brien, K. P. (1988). Longitudinal-Study of Emotional, Social, and Physical Changes after Traumatic Brain Injury. Journal of Learning Disabilities, 21(8), 456-463. doi: 10.1177/002221948802100802

Lovibond, S. H., \& Lovibond, P. F. (1995). Manual for the Depression Anxiety and Stress Scales. (2nd ed.). Sydney: Psychological Foundation.

Malia, K., Powell, G., \& Torode, S. (1995). Personality and psychosocial function after brain injury. Brain Injury, 9(7), 697-712. 
671 Marsh, N. V., \& Knight, R. G. (1991). Behavioral assessment of social competence following

672

673

674

675

676

677

678

679

680

681

682

683

684

685

686

687

688

689

690

691

692

693

694

695 severe head injury. Journal of Clinical and Experimental Neuropsychology, 13(5), 729-740.

McDonald, S., Flanagan, S., Martin, I., \& Saunders, C. (2004). The ecological validity of TASIT: A test of social perception. Neuropsychological Rehabilitation, 14(3), 285302. doi: $10.1080 / 09602010343000237$

McDonald, S., Hunt, C., Henry, J. D., Dimoska-Di Marco, A., \& Bornhofen, C. (2010). Angry responses to emotional events: The role of impaired control and drive in people with severe traumatic brain injury. Journal of Clinical and Experimental Neuropsychology, 32(8), 855-864. doi: 10.1080/13803391003596405

McKinlay, W., Brooks, N., Bond, M., Martinage, D., \& Marshall, M. (1981). The short-term outcome of severe blunt head injury as reported by relatives of the injured persons. Journal of Neurology, Neurosurgery \& Psychiatry, 44(6), 527-533. doi: 10.1136/jnnp.44.6.527

Milders, M., Fuchs, S., \& Crawford, J. R. (2003). Neuropsychological impairments and changes in emotional and social behaviour following severe traumatic brain injury. Journal of Clinical and Experimental Neuropsychology, 25(2), 157-172. doi: 10.1076/jcen.25.2.157.13642

Monsalve, B. C., Guitart, M. B., Lopez, R., Vilasar, A. B., \& Quemada, J. I. (2012). Psychopatological evaluation of traumatic brain injury patients with the Neuropsychiatric Inventory. Revista De Psiquiatria Y Salud Mental, 5(3), 160-166. doi: 10.1016/j.rpsm.2012.02.004

Morton, M., \& Wehman, P. (1995). Psychosocial and emotional sequelae of individuals with traumatic brain injury: a literature review and recommendations. Brain Injury, 9(1), 81-92. 
696 Namiki, C., Yamada, M., Yoshida, H., Hanakawa, T., Fukuyama, H., \& Murai, T. (2008).

697

698

699

700

701

702

703

704

705

706

707

708

709

710

711

712

713

714

715

716

717

718

719

720 Small orbitofrontal traumatic lesions detected by high resolution MRI in a patient with major behavioural changes. Neurocase, 14(6), 474-479. doi: $10.1080 / 13554790802459494$

Oddy, M., Coughlan, T., Tyerman, A., \& Jenkins, D. (1985). Social adjustment after closed head injury: a further follow-up seven years after injury. Journal of Neurology, Neurosurgery \& Psychiatry, 48(6), 564-568.

Ponsford, J. L., Olver, J. H., \& Curran, C. (1995). A Profile of Outcome - 2 Years after Traumatic Brain Injury. Brain Injury, 9(1), 1-10. doi: 10.3109/02699059509004565

Prigatano, G. P. (1992). Personality disturbances associated with traumatic brain injury. Journal of Consulting and Clinical Psychology, 60(3), 360.

Prigatano, G. P., Pepping, M., \& Klonoff, P. (1986). Cognitive, personality, and psychosocial factors in the neuropsychological assessment of brain-injured patients. Clinical neuropsychology of intervention (pp. 135-166): Springer US.

Rochat, L., Ammann, J., Mayer, E., Annoni, J.-M., \& Van der Linden, M. (2009). Executive disorders and perceived socio-emotional changes after traumatic brain injury. Journal of Neuropsychology, 3(2), 213-227. doi: 10.1348/174866408X397656

Russell, W. R., \& Smith, A. (1961). Post-traumatic amnesia in closed head injury. Archives of Neurology, 5(1), 4-17.

Shin, I.-S., Carter, M., Masterman, D., Fairbanks, L., \& Cummings, J. L. (2005). Neuropsychiatric Symptoms and Quality of Life in Alzheimer Disease. The American Journal of Geriatric Psychiatry, 13(6), 469-474. doi: 10.1176/appi.ajgp.13.6.469 15956266

Shrout, P. E., \& Fleiss, J. L. (1979). Intraclass correlations: Uses in assessing rater reliability. Psychological Bulletin, .86(2), pp. doi: 10.1037/0033-2909.86.2.420 18839484 
Spreen, O., \& Strauss, E. (1991). Controlled oral word association (word fluency). Spreen O, Strauss E. A compendium of neuropsychological tests. Oxford: Oxford Univ Pr, Oxford: Oxford University Press., 219-270.

Tate, R. L. (1999). Executive dysfunction and characterological changes after traumatic brain injury: Two sides of the same coin? Cortex, 35(1), 39-55.

Tate, R. L., Hodgkinson, A., Veerabangsa, A., \& Maggiotto, S. (1999). Measuring psychosocial recovery after traumatic brain injury: Psychometric properties of a new scale. The Journal of Head Trauma Rehabilitation, 14(6), 543-557.

Thomsen, I. V. (1984). Late outcome of very severe blunt head trauma: a 10-15 year second follow-up. Journal of Neurology, Neurosurgery \& Psychiatry, 47(3), 260-268.

Votruba, K. L., Rapport, L. J., Vangel, S. J., Jr., Hanks, R. A., Lequerica, A., Whitman, R. D., \& Langenecker, S. (2008). Impulsivity and traumatic brain injury: The relations among behavioral observation, performance measures, and rating scales. The Journal of Head Trauma Rehabilitation, 23(2), 65-73. doi: 10.1097/01.HTR.0000314525.93381.69 18362760

Wechsler, D. (1997). Wechsler Adult Intelligence Scale-Third Edition (WAIS-III). San Anontio, TX: Psychological Corporation.

Winkler, D., Unsworth, C., \& Sloan, S. (2006). Factors that lead to successful community integration following severe traumatic brain injury. The Journal of Head Trauma Rehabilitation, 21(1), 8-21. doi: 10.1097/00001199-200601000-00002 16456388 
Table 1

Means, standard deviations and results of group comparisons on demographic, emotional and cognitive variables for the TBI and comparison groups

\begin{tabular}{|c|c|c|c|}
\hline & \multicolumn{2}{|c|}{ Mean (SD) } & \multirow[b]{2}{*}{$\operatorname{Diff}(p)$} \\
\hline & TBI $(N=22)$ & Comparison $(N=21)$ & \\
\hline \multicolumn{4}{|l|}{ Demographics } \\
\hline PTA (days) & $64.57(46.52)$ & & \\
\hline Age & $50.45(14.30)$ & $45.29(13.70)$ & .233 \\
\hline Years of education & $12.80(2.37)$ & $14.52(1.69)$ & .008 \\
\hline Preinjury Occupation & & & .193 \\
\hline Unskilled trade/unemployed & 3 & 3 & \\
\hline Skilled trade & 1 & 0 & \\
\hline Business owner & 2 & 1 & \\
\hline Prof/managerial & 10 & 10 & \\
\hline Student & 6 & 7 & \\
\hline \multicolumn{4}{|l|}{ Disinhibition } \\
\hline Observed Disinhibition Rating & $10.14(3.09)$ & $8.69(.94)$ & .049 \\
\hline Hayling Error Scaled Score & $5.55(1.97)$ & & \\
\hline COWAT Error Score & $2.73(2.35)$ & & \\
\hline \multicolumn{4}{|l|}{ Emotional Functioning } \\
\hline DASS Total & $33.09(29.71)$ & $10.57(11.65)$ & .003 \\
\hline DASS Depression & $11.64(12.60)$ & $3.33(4.95)$ & .008 \\
\hline DASS Anxiety & $8.64(8.91)$ & $.95(1.63)$ & .001 \\
\hline DASS Stress & $13.73(12.19)$ & $6.29(9.19)$ & .029 \\
\hline \multicolumn{4}{|l|}{ Executive Functioning } \\
\hline Digit Span & $10.09(2.33)$ & & \\
\hline Symbol Code & $7.33(2.87)$ & & \\
\hline
\end{tabular}


Table 2

Correlations between informant-reported disinhibition, observed disinhibition and neuropsychological variables in the TBI group $(N=22)$

\begin{tabular}{|c|c|c|c|c|c|c|}
\hline & $\begin{array}{l}\text { NPI } \\
\text { total } \\
\text { score }\end{array}$ & $\begin{array}{l}\text { Mean } \\
\text { disinhibition } \\
\text { rating }\end{array}$ & $\begin{array}{l}\text { Hayling } \\
\text { scaled } \\
\text { error } \\
\text { score }\end{array}$ & $\begin{array}{l}\text { COWAT } \\
\text { error } \\
\text { score }\end{array}$ & $\begin{array}{l}\text { Digit } \\
\text { span }\end{array}$ & $\begin{array}{l}\text { Digit symbol } \\
\text { coding }\end{array}$ \\
\hline \multicolumn{7}{|c|}{ Informant-Reported Disinhibition } \\
\hline NPI Total Score & & .38 & .34 & $.70^{* *}$ & $.48^{*}$ & .26 \\
\hline \multicolumn{7}{|l|}{ Observed Disinhibition } \\
\hline Disinhibition mean rating & .38 & & .14 & .41 & .07 & -.09 \\
\hline \multicolumn{7}{|c|}{ Neuropsychological Disinhibition } \\
\hline Hayling error scaled score & .34 & .14 & & .30 & .09 & .19 \\
\hline COWAT error score & $.70^{* *}$ & .41 & .30 & & .19 & $.52 *$ \\
\hline \multicolumn{7}{|l|}{ Neuropsychological Exec Func } \\
\hline Digit span & $.48^{*}$ & .07 & .09 & .19 & & .09 \\
\hline Digit symbol coding & .26 & -.09 & .19 & $.52 *$ & .09 & \\
\hline
\end{tabular}

Note. Exec Func $=$ Executive Functioning. * Significant at $p<.05 . * *$ Significant at $p<.001$. 
Table 3

Multiple regressions predicting social disinhibition ratings and NPI-D total score from four neuropsychological variables

\begin{tabular}{lcccc}
\hline & \multicolumn{2}{c}{ Social Disinhibition Ratings } & \multicolumn{2}{c}{ NPI Disinhibition total Score } \\
\cline { 2 - 5 } Variable & $\mathrm{B}$ & $\beta$ & $\mathrm{B}$ & $\beta$ \\
\hline Constant & 10.27 & & -3.78 & \\
Digit Span & .09 & .07 & .42 & .37 \\
Digit Symbol Code & -.50 & -.45 & -.09 & -.10 \\
COWAT Error & $1.05^{*}$ & $.69^{*}$ & $.68^{*}$ & $.55^{*}$ \\
Hayling Error & -.001 & -.001 & .24 & .19 \\
& & & & $.39^{*}$ \\
Adjusted $\mathrm{R}^{2}$ & & .21 & & $4.24^{*}$ \\
F & & 2.31 & & \\
\hline
\end{tabular}

Note. $\mathrm{N}=21 * \mathrm{p}<.05$ 
Table 4

The most frequently endorsed metric items of the disinhibition domain of the

Neuropsychiatric Inventory (NPI-D)

\begin{tabular}{llc}
\hline Response item & $\begin{array}{l}\text { Number of } \\
\text { Participants }\end{array}$ & Percentage \\
\hline Does he/she act impulsively without thinking of the consequences & 12 & $54 \%$ \\
$\begin{array}{l}\text { Does he/she talk to strangers as if they knew them } \\
\begin{array}{l}\text { Does he/she say things to people that are insensitive or hurt their } \\
\text { feelings }\end{array}\end{array}$ & 8 & $50 \%$ \\
$\begin{array}{l}\text { Does he/she talk openly about very personal or private matters not } \\
\text { usually discussed in public }\end{array}$ & 5 & $23 \%$ \\
$\begin{array}{l}\text { Does he/she show other signs of loss of control of his/her impulses } \\
\text { Does he/she say crude things or make inappropriate sexual remarks }\end{array}$ & 5 & $11 \%$ \\
$\begin{array}{l}\text { Does he/she fondle, touch or hug others in a way that is not } \\
\text { appropriate }\end{array}$ & 1 & $9 \%$ \\
\hline
\end{tabular}

